\title{
Emerging Patterns of Social Identification in Postapartheid South Africa
}

\author{
Elirea Bornman* \\ University of South Africa
}

Theorists acknowledge the possibility of multiple group identification where groups are imbedded in hierarchical structures that can change as the environment changes. This article investigates national, subnational, and supranational identification and the possible impact of social and political change on identity structures in South Africa. The results of three surveys conducted in 1994, 1998, and 2001 are discussed. While national and African identities have apparently strengthened among Blacks since 1994, national identification seems to have diminished among Afrikaans-speaking Whites in favor of ethnic identification. Some potential consequences of and directions for future research are discussed.

Social identity theory holds that we integrate membership of social groups as the social component of our self-concepts (Tajfel, 1981), implying that the self is at least partially defined by membership of social groups. The social and political position of the ingroup (or own group) in relation to relevant outgroups (or other groups) consequently becomes psychologically significant and can be associated with various forms of social and political behavior.

Analysts acknowledge the possibility of individuals identifying with multiple social groups (Deaux, 1993). Deaux proposes a hierarchical structure in which identities at the top — usually related to nationality, race, ethnicity, and/or cultureare usually of a more primary and extensive nature, are relevant in a number of situations, and have a more profound influence on attitudes and behavior. Identities lower down the hierarchical structure are usually related to specific interest groups, age groups, hobby groups, or professional groups.

* Correspondence concerning this article should be addressed to Elirea Bornman, Department of Communication Science, University of South Africa, Cape Town, South Africa [e-mail: bornme@unisa.ac.za].

The author thanks the John D and Catherine T MacArthur Foundation for a grant that made the research for the third study reported in this article possible. The author is willing to send breakdowns of the data in terms of demographic variables to any person who is interested. 
Identity structures are, however, never static but dynamic (Deaux, 1993; Korf \& Malan, 2002). Changes in identity structures often concur with changes in the social and political environment such as rearrangements regarding the composition of groups, the social organization of groups in the context, a revision of ideologies, disturbances in the social environment that disrupt existing group relations, and/or a reevaluation of the characteristics that society associates with particular groups. Social and/or political change usually compels individuals to confront and reevaluate their alliances with particular groups.

Since 1994, South Africans of all racial, ethnic, and cultural groups have been subjected to large-scale social and political change that could have far-reaching implications for identity structures (Bekker, 1999). This article investigates emerging patterns of social identification among South Africans, both during and after the advent of a new political dispensation, to obtain some idea of the impact of these changes on identity structures.

\section{The Interface between National, Subnational, and Supranational Identities}

An important factor for social and political stability in heterogeneous societies is the interface between identification with subnational groups (ethnic and/or racial groups), so-called national (nation-state) identification, and identification with supranational power blocs in an increasingly globalizing environment.

Heterogeneous states, in particular, face the possibility of multiple and often contending social identities (Mattes, 1999). Social identities and associated loyalties are believed to be torn between subnational groups and the larger political community represented by the nation-state. It is believed that those who perceive themselves as members of the group that holds power will identify more easily with the government/state. Groups on the periphery of power, on the other hand, will often feel marginalized and identify less with the state. Heterogeneous states therefore, almost by definition, lack a common agreement on social identity or a common nationhood.

Subnational versus national identification is furthermore complicated by the changes associated with globalization (Bauman, 1998). To function effectively within the emerging global environment, nation-states seek alliances with other nation-states in supranational power blocks. As a nation-state surrenders at least part of its legitimacy, sovereignty, and authority to such power blocs, these power blocs can make a claim - if only partly-on citizens' collective identity. The nation-state is consequently no longer the only or principal political and territorial entity in which citizenship and collective identity can reside. Many of these power blocs also consciously strive to forge supranational identities. The prevailing discourses and identity struggles associated with the European Union exemplify this (Schopflin, 1997). 


\section{Identity Struggles within South African Society}

Most analysts regard South African society as heterogeneous, complex, and deeply segmented not only on the basis of culture, race, historical background, language, and religion, but also on economic and/or class status (Human Sciences Research Council [HSRC], 1987).

Horowitz (1991) holds that identity formation during the apartheid era was primarily determined by the official system of racial classification ascribed to an individual at birth. This racial stratification-currently still used in official governmental policy and publications-recognized four population groups: Blacks, Whites, Coloureds (defined as a non-White group of mixed racial descent), and Asians/Indians (HSRC, 1987). There are, however, also language, cultural, and/or ethnic differences within the major racial groups. Within the larger White community, Afrikaans- and English-speaking Whites are regarded as two different language and/or cultural groups. The relationship between these two White ethnic/ cultural groups has a legacy of conflict and polarization, such as during the AngloBoer War (1899-1902), when they fought for, or supported, different sides, and to a slight extent in the apartheid era, when English speakers were more likely to oppose apartheid (Finchilescu \& Tredoux, this issue; HSRC, 1987). Among Blacks, nine language groups are officially recognized, namely, Sepedi, Sesotho, Setswana, siSwati, Tshivenda, Xitsonga, isiNdebele, isiXhosa, and isiZulu (see Figure 1).

Social analysts also agree that the construction of a South African national identity during the apartheid era was divisive and exclusionary as racial divisions were reified and groups of color were excluded from obtaining formal citizenship (Eaton, 2002). It is not surprising therefore that the issue of a South African national identity became the topic of heated debate during the transition to a new political dispensation. It was agreed that the country lacked a commonly accepted national identity and a sense of nationhood. An ideology of new nationalism and/or nation building was consequently perceived as the logical step to filling the gap left by apartheid.

Thus the political transformation led to the invention of the "new South Africa" as the central concept in the nation-building initiative. This ideal is embodied in new national symbols and the metaphor of the "Rainbow Nation," which emphasizes unity among the diversity of South African people (Bornman, 2006). However, Eaton (2002) indicates that since 1997 there has been a distinct shift from the overwhelming nation-building discourse of the transitionary period. Even before the advent of a new political dispensation, the African National Congress (ANC) and Pan African Council held strong Africanist, rather than exclusively South African, identities. The ANC leadership under President Mbeki increasingly steered away from the nation-building discourse of the Mandela era and embraced Africanism. Terms such as the "African Renaissance" and "an African 


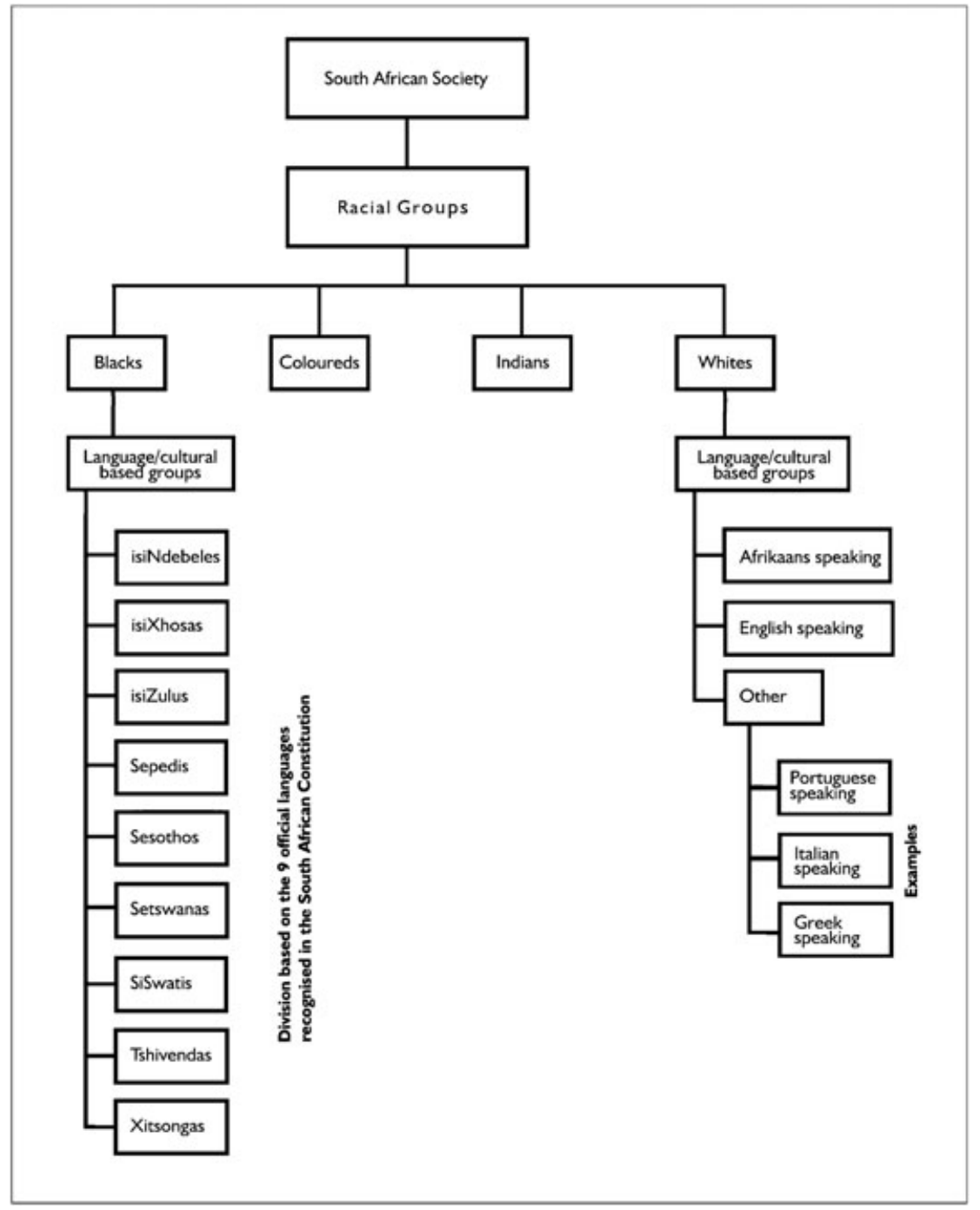

Fig. 1. Composition of South African society.

century" are increasingly being used. The question of whether Whites are regarded as Africans has become a key issue in identity-related discourse. The so-called new South Africa is consequently no exception to the challenge of contending identity politics (Bekker, 1999).

Horowitz (1991) also warned that loyalty to ethnic, racial, or other subnational groups would not necessarily become irrelevant once ethnic and racial equality 
has been achieved within a democratic system. In the new political arena, South Africans may experience a greater need to identify themselves by contrast, to emphasize social borders, and to confirm their ethnic, cultural, and/or racial identities. It can thus be proposed that racial and ethnic identities might not only persist, but could be integrated in a complex fashion within the new environment, and this could give rise to new ways in which "us" and "them" are defined (Erasmus, this issue; Soudien, this issue).

Furthermore, with the advent of a new political dispensation, South Africa has been readmitted to world society and thus has had to confront a radically altered and fast-globalizing world with all its paradoxical tendencies and impulses (Le Pere \& Lambrechts, 1999). Like other governments worldwide, the new government is forced to form new allegiances with the international community and negotiate its national identity. As South Africa intensifies its engagement with the world, national identity formation and identification with subnational groups will probably have to contend, in dialectic fashion, not only with inherent differences, but also with the possibility of multiple identities in the complex new world order. Supranational identification with Africanism and/or the African continent is, for example, probably enhanced by South Africa's membership of the Southern African Development Community and the African Union. The domination of Western culture and the Western world in the global system can increase or reify identification with the West especially among Whites. Globalization may also result in South African citizens becoming not only increasingly aware of their membership of the global community, but also increasingly identifying with various global societies (Bornman, 2003). Emerging patterns of social identification and changes in identity structures among South Africans could thus potentially be determined not only by historical and current societal and political factors within South Africa itself, but also by factors within the larger African region as well as the new global order of which the country has become an integral part.

Research conducted both before and after the political transition confirms the coexistence of national and subnational identities within South African society. During the apartheid era, the HSRC (1987) found strong ethnic identification and identification with the broader White community among Afrikaans-speaking Whites, while the primary social identities of English-speaking Whites were a broad South Africanism and an identification with the broader White community. Although strong overarching racial identification was found for Blacks, identification with Black ethnic groups was surprisingly strong given the background of Black resistance against apartheid, whereas Coloureds rejected a colored identity. (No findings for Indians were reported.) In 1994, the Institute for a Democratic South Africa found that race and ethnicity remained important social identities shortly after the advent of a new dispensation (Mattes, 1994). Large majorities of supporters of all Black political parties as well as the National Party indicated they were members of groups distinguished by ethnic characteristics such 
as culture, history, or language and rated their language and culture as important. Gibson and Gouws (2000) indicate an emerging African identity. They found that "Africans" was the label mostly preferred by Blacks to describe themselves, while the majority of Whites preferred the label "South Africans." In response to a question in which they had to indicate the group with which they most strongly did not identify, many respondents did not indicate an "anti-identity." "Boers" and "Afrikaners" were, however, the strongest anti-identities for Blacks and "Blacks" for Whites. In a series of studies conducted from 1997 to 2000, Klandermans, Roefs, and Olivier (2001) found large fluctuations among the subnational identities of Blacks, Coloureds, and Indians in the first years of the new dispensation, while those of Whites remained relatively stable. However, despite fluctuations, ethnic identities remained important to all groups, while identities associated with religion were also important to Coloureds and Indians. Questions on national identification included from 1997 indicated that, despite strong ethnic identification, the large majority of all South Africans felt proud to be called South Africans. A longitudinal cohort study among adolescents by Finchilescu and Dawes (1999) indicated that though Black adolescents and English-speaking Whites did not show much change in the level of endorsement for a South African identity, significantly larger proportions of Coloureds, Indians, and Afrikaans-speaking Whites endorsed a South African identity in 1996 compared to 1992. However, ethnic identification also increased from 1992 to 1996 for all groups except Indians.

In the present article, I report results of three studies conducted to answer controversial questions concerning emerging patterns of social identification in South Africa, during and after the advent of a new political dispensation. Although the nature of the samples and measuring instruments differ, all three studies aimed to shed light on potential sources of social identification and their relative importance during a period of large-scale social and political change.

The first study was conducted in January 1994 on the eve of the advent of a new political dispensation in April 1994 in the so-called Pretoria-WitwatersrandVereeniging area (Gauteng province). At the time of the second study, conducted in October/November 1998, more than 4 years had passed since the advent of a new political dispensation, and the country stood on the brink of the second general elections of 1999. The third study was conducted in August/September 2001 and formed part of a broader study into the relationship between identity, democratization, and globalization.

In these studies race was regarded as a form of group categorization, based on a combination of phenotypical characteristics of genetic origin (Helms, 1990). Ethnicity was seen as a complex and multidimensional form of group categorization related to perceptions of kinship, a common cultural focus and a common historical heritage (Van den Berghe, 1981). Although race per se can become a source of social identification, it can also serve as an indicator of kinship and consequently become a distinguishing element of the ethnic identity for a particular 
group. Language is regarded as one of the most important dimensions of culture and a powerful symbol of ethnicity (Sleek, 1993).

\section{Study 1}

\section{Method}

Two separate samples of 500 Blacks and 500 Whites aged 18 years or older were drawn in the Pretoria-Witwatersrand-Vereeniging area by means of random multistage cluster sampling. The samples were drawn from traditionally Black and White residential areas, respectively. Questionnaires were completed in Afrikaans and English during personal interviews. Black interviewers were trained to explain questions in vernacular languages. The final realized samples consisted of 460 Whites (of whom 347 were Afrikaans speaking and 113 English speaking) and 466 Blacks.

Respondents indicated on a 5-point scale the extent to which they identified with South Africans, Africans, Blacks, Whites, Afrikaans-speaking Whites (or Afrikaners), English-speaking Whites, and Black ethnic/language groups. A score of (5) indicated to a large degree and (1) indicated not at all.

Multivariate analysis of variance was performed as an omnibus test of differences, with follow-up analysis of between-group differences for each measured social category. Tukey's Honestly Significant Difference (HSD) tests were conducted, where appropriate, on all pairs of means to determine the nature of group differences. Partial eta squared values $\left(\eta_{p}^{2}\right)$ of effect size were computed. A distinction was made between Afrikaans- and English-speaking Whites as the political transition could potentially have the most far-reaching effects on Afrikaansspeaking Whites, the group in power before 1994. This distinction was retained in the analyses of the data of the subsequent studies. Within-group differences were determined by repeated measures analysis of variance.

\section{Results}

The Wilks's lambda statistic of .022 for the overall effect of the groups on the seven dependent variables for the multivariate analysis of variance was approximated by $F(2,920)=5,805.535, p<.001$. Subsequent univariate analyses indicated no significant differences between the three groups for identification with South Africa (see Table 1) —all three groups had statistically equivalent means for this variable, $F(2,920)=0.311, p=.733, \eta_{p}^{2}=.001$.

In contrast, exceptionally large between-group differences existed for identification with Afrikaners/Afrikaans-speaking Whites, $F(2,920)=1,053.392$, $p<.001, \eta_{p}^{2}=.696$. Similarly high levels of between-group differences were 
Table 1. Means, Standard Deviations, and Results of Tukey's HSD Tests for the Three Studies

\begin{tabular}{|c|c|c|c|c|c|c|c|c|c|c|}
\hline & \multicolumn{2}{|c|}{ Blacks } & \multicolumn{2}{|c|}{ Coloureds } & \multicolumn{2}{|c|}{ Indians } & \multicolumn{2}{|c|}{$\begin{array}{l}\text { Afrikaans- } \\
\text { Speaking } \\
\text { Whites }\end{array}$} & \multicolumn{2}{|c|}{$\begin{array}{l}\text { English- } \\
\text { Speaking } \\
\text { Whites }\end{array}$} \\
\hline & $M$ & $S D$ & $M$ & $S D$ & $M$ & $S D$ & $M$ & $S D$ & $M$ & $S D$ \\
\hline \multicolumn{11}{|l|}{ First Study—1994 } \\
\hline South Africans & $4.7^{\mathrm{a}}$ & 0.8 & & & & & $4.7^{\mathrm{a}}$ & 0.7 & $4.7^{\mathrm{a}}$ & 0.6 \\
\hline Africans & $4.3^{\mathrm{c}}$ & 1.0 & & & & & $3.2^{\mathrm{a}}$ & 1.4 & $3.6^{\mathrm{b}}$ & 1.3 \\
\hline Blacks & $4.8^{\mathrm{c}}$ & 0.6 & & & & & $2.7^{\mathrm{a}}$ & 1.4 & $3.3^{\mathrm{b}}$ & 1.3 \\
\hline Whites & $2.7^{\mathrm{a}}$ & 1.3 & & & & & $3.8^{\mathrm{b}}$ & 1.2 & $4.3^{\mathrm{c}}$ & 1.0 \\
\hline Black ethnic group & $4.6^{\mathrm{c}}$ & 0.9 & & & & & $2.9^{\mathrm{a}}$ & 1.3 & $3.4^{\mathrm{b}}$ & 1.2 \\
\hline Afrikaners & $1.8^{\mathrm{a}}$ & 1.1 & & & & & $4.8^{\mathrm{c}}$ & 0.6 & $3.9^{\mathrm{b}}$ & 1.1 \\
\hline $\begin{array}{l}\text { English-speaking } \\
\text { Whites }\end{array}$ & $2.9^{\mathrm{a}}$ & 1.4 & & & & & $4.2^{\mathrm{b}}$ & 0.9 & $4.7^{\mathrm{c}}$ & 0.6 \\
\hline \multicolumn{11}{|l|}{ Second Study -1998} \\
\hline $\begin{array}{l}\text { Pride in being a } \\
\text { South African }\end{array}$ & $4.6^{\mathrm{c}}$ & 0.7 & $4.3^{\mathrm{a}, \mathrm{b}}$ & 0.9 & $4.3^{\mathrm{b}}$ & 0.9 & $4.3^{\mathrm{b}}$ & 0.9 & $4.0^{\mathrm{a}}$ & 0.8 \\
\hline Language group & $3.8^{\mathrm{c}}$ & 1.0 & $3.4^{\mathrm{a}, \mathrm{b}}$ & 0.9 & $3.4^{\mathrm{a}}$ & 0.6 & $3.7^{\mathrm{b}, \mathrm{c}}$ & 1.0 & $3.2^{\mathrm{a}}$ & 1.0 \\
\hline Racial group & $3.6^{\mathrm{c}}$ & 1.0 & $3.5^{\mathrm{b}, \mathrm{c}}$ & 0.9 & $3.3^{\mathrm{b}}$ & 0.7 & $3.7^{\mathrm{c}}$ & 1.0 & $2.9^{\mathrm{a}}$ & 1.1 \\
\hline Ethnic group & $3.6^{\mathrm{c}}$ & 1.0 & $3.4^{\mathrm{b}, \mathrm{c}}$ & 0.8 & $3.2^{\mathrm{b}}$ & 0.8 & $3.1^{\mathrm{b}}$ & 1.2 & $2.7^{\mathrm{a}}$ & 1.0 \\
\hline \multicolumn{11}{|l|}{ Third Study_-2001 } \\
\hline Rainbow Nation & $4.3^{\mathrm{b}, \mathrm{c}}$ & 1.0 & $4.1^{\mathrm{b}, \mathrm{c}}$ & 1.0 & $4.5^{\mathrm{c}}$ & 0.7 & $3.7^{\mathrm{a}}$ & 1.2 & $4.1^{\mathrm{b}}$ & 1.2 \\
\hline South African state & $4.0^{\mathrm{b}}$ & 1.0 & $3.9^{\mathrm{a}, \mathrm{b}}$ & 1.0 & $4.2^{\mathrm{b}}$ & 0.7 & $3.7^{\mathrm{a}}$ & 1.2 & $4.1^{\mathrm{b}}$ & 1.2 \\
\hline Own racial group & $4.2^{\mathrm{a}, \mathrm{b}}$ & 1.1 & $3.9^{\mathrm{a}}$ & 1.1 & $4.4^{\mathrm{b}}$ & 0.7 & $4.1^{\mathrm{a}, \mathrm{b}}$ & 1.0 & $3.9^{\mathrm{a}}$ & 1.2 \\
\hline Own ethnic group & $4.3^{\mathrm{a}, \mathrm{b}}$ & 1.0 & $4.0^{\mathrm{a}}$ & 1.1 & $4.4^{\mathrm{b}}$ & 0.8 & $4.2^{\mathrm{a}, \mathrm{b}}$ & 1.0 & $4.2^{\mathrm{a}, \mathrm{b}}$ & 1.1 \\
\hline African culture & $4.4^{\mathrm{c}}$ & 1.0 & $3.8^{\mathrm{b}}$ & 1.2 & $4.3^{\mathrm{c}}$ & 0.9 & $3.2^{\mathrm{a}}$ & 1.2 & $3.6^{\mathrm{a}, \mathrm{b}}$ & 1.3 \\
\hline Western world & $3.0^{\mathrm{a}}$ & 1.2 & $3.2^{\mathrm{a}, \mathrm{b}}$ & 1.2 & $3.4^{\mathrm{b}}$ & 1.2 & $3.5^{\mathrm{b}}$ & 1.1 & $3.9^{\mathrm{c}}$ & 1.1 \\
\hline Western culture & $2.8^{\mathrm{a}}$ & 1.2 & $3.0^{\mathrm{a}, \mathrm{b}}$ & 1.1 & $3.3^{\mathrm{b}, \mathrm{c}}$ & 1.2 & $3.4^{\mathrm{c}}$ & 1.1 & $4.0^{\mathrm{d}}$ & 1.0 \\
\hline Global community & $3.4^{\mathrm{a}}$ & 1.3 & $3.4^{\mathrm{a}, \mathrm{b}}$ & 1.2 & $3.8^{\mathrm{b}, \mathrm{c}}$ & 1.0 & $3.5^{\mathrm{a}, \mathrm{b}, \mathrm{c}}$ & 1.2 & $3.9^{\mathrm{c}}$ & 1.1 \\
\hline
\end{tabular}

Note. ${ }^{\mathrm{a}, \mathrm{b}, \mathrm{c}}$ Means that are significantly different in the comparisons across groups are marked with different letters.

found for identification with Blacks, $F(2,920)=442.103, p<0.001, \eta_{p}^{2}=$ .490. The resistance against Afrikaans-speaking Whites could perhaps be ascribed to resistance against Afrikaner domination during apartheid. The large between-group differences for identification with Blacks could furthermore indicate a degree of fear and resistance among Whites regarding Black domination in a new political dispensation. The results of analyses of variance for the other dependent variables are as follows: Africans, $F(2,920)=84.645, p<0.001$, $\eta_{p}^{2}=.155$; Whites $F(2,920)=123.467, p<0.001, \eta_{p}^{2}=.212$; Black ethnic 
group $F(2,920)=240.715, p<.001, \eta_{p}^{2}=.344$; English-speaking Whites $F(2,920)=199.813, p<.001, \eta_{p}^{2}=.303$.

Post-hoc Tukey HSD tests revealed contrasting patterns for Blacks, on the one hand, and the two White groups on the other hand. Blacks identified significantly more strongly than the two White groups with identities related to their race and culture/ethnicity, namely, Africans, Blacks, and a Black ethnic group. In contrast, Afrikaans-speaking Whites identified significantly less with Black-related categories than both Blacks and English-speaking Whites. On the other hand, though English-speaking Whites identified significantly less with these categories than Blacks, they nevertheless identified significantly more than Afrikaans-speaking Whites. A contrasting pattern is furthermore reflected in the means for categories associated with Whites. Blacks identified significantly less than both White groups with White-related categories, namely Whites, Afrikaners/Afrikaans-speaking Whites, and English-speaking Whites. Afrikaans-speaking Whites identified significantly more strongly with their ethnic group (Afrikaners) than did the other two groups. Similarly, English-speaking Whites identified significantly more than the other two groups with their ethnic group (English-speaking Whites). Surprisingly, English-speaking Whites identified significantly more strongly with Whites than did Afrikaans-speaking Whites, indicating that a racial identity was less important to Afrikaans-speaking Whites than to English-speaking Whites.

The results of the repeated measures model revealed that significant withingroup differences existed, $F(12,5,520)=389.08, p<.0001, \eta_{p}^{2}=0.458$. Although Blacks identified most highly with their racial group (Blacks), the differences between the three categories that Blacks rated the highest-Blacks, South Africans, and Black ethnic groups-were not statistically significant. However, Blacks identified significantly more strongly with these three categories than with Africans. Blacks furthermore identified significantly more strongly with South Africans, Africans, and the other Black-related categories than with the various White-related categories. With regard to Afrikaans-speaking Whites, no significant differences were found between their relatively strong identification with South Africans and Afrikaners (Afrikaans-speaking Whites), but they identified significantly more strongly with these two categories than with all the other categories. A similar pattern emerged for English-speaking Whites. Although no significant differences were found for identification with South Africans, Englishspeaking Whites, and Whites, significant differences were found between these three categories and all the other categories. Thus, the general identification pattern for all three groups was a divide between identities associated with their own race and ethnic group, and those related to the other race group. However, in all groups, identification as South African was as strong as their race/ethnic identities. 


\section{Study 2}

\section{Method}

The October/November 1998 study formed part of a composite questionnaire survey conducted by Market Research Africa on behalf of the HSRC. A multistage stratified cluster sample comprised all racial groups, provinces, and rural and urban areas was drawn. Questionnaires were completed in Afrikaans and English during personal interviews. Questions were explained in vernacular languages. The final realized sample consisted of 2,171 respondents, aged 18 years or older, of whom 1,472 (67.5\%) were Black, 204 (9.3\%) Coloured, 69 (3.2\%) Indian/Asian, and 426 (20.0\%) White (of which 306 were Afrikaans speaking and 120 English speaking).

Respondents rated their pride in being South African on a 5-point scale. A score of (5) indicated very proud and (1) not proud at all. Emotional attachment (closeness) to social groups was determined by means of a 5-point scale ranging from extremely close (5) to not close (1). As the response options for the pride variable differed from those of the closeness variables, a separate one-way analysis of variance was conducted, taking pride as the dependent variable and group membership as the independent variable. Multivariate analysis of variance was performed to determine the overall existence of differences as well as betweengroup differences for the closeness variables, similar to the analyses conducted for Study 1.

\section{Results}

For all the groups, mean scores for pride in being South African were significantly higher than all the closeness measures (see Table 1). These differences could be due to variations in the wording of the questions. Although the means for all the groups were 4.0 or above for pride in being a South African-an indication of positive nationalism among most South Africans in 1998 - significant between-group differences were indicated, $F(4,2,138)=36.163, p<.001, \eta_{p}^{2}=$ .063. Blacks indicated significantly more pride in being South African than did any other group, while English-speaking Whites showed the least pride.

Despite the overall high levels of pride in being South African, the closeness measures indicate that subnational groups remained important. Group differences on the three closeness variables were significant, $F(4,2,143)=18.566 ; p<.001$; $\eta_{p}^{2}=.033$. The results of the subsequent univariate analyses for the respective closeness measures were: language group, $F(4,2,143)=13.026, p<.001, \eta_{p}^{2}=$ .024 ; racial group, $F(4,2,143)=17.503, p<.001, \eta_{p}^{2}=.032$; ethnic group, $F(4,2,143)=36.879, p<.001, \eta_{p}^{2}=.064$. When effect sizes are compared, pride in being South African and closeness to ethnic groups gave rise to the largest differences of opinion. 
In addition to indicating the most pride in being South African, Blacks also indicated significantly more closeness to their language, racial and ethnic groups than did most other groups. While Blacks and Afrikaans-speaking Whites did not differ significantly, these two groups were significantly closer to their respective language groups than Coloureds, Indians, and English-speaking Whites. Englishspeaking Whites were also significantly less close than all the other groups (with the exception of Coloureds and Indians, in the case of closeness to language groups) to all the categories investigated.

Blacks were significantly closer to their language group than to their racial and ethnic groups, between which statistically equivalent scores were reported. For Coloureds and Indians, no significant differences were found between the mean scores for closeness to their respective language, ethnic and racial groupsan indication that Coloureds and Indians did not really differentiate between these categories. Afrikaans-speaking Whites indicated significantly more closeness to their language and racial group than to their ethnic group, while the difference between language and racial groups was not significant. English-speaking Whites were significantly closer to their language group than to their ethnic group. The differences between closeness to their language and racial groups and their ethnic and racial groups were, however, not significant. As most groups-with the exception of Coloureds-indicated more closeness to their language than to their ethnic groups, it appears that language might be the most important level of subnational identification in South Africa.

\section{Study 3}

\section{Method}

The 2001 study also formed part of a composite survey conducted by the Community Agency for Social Enquiry for the HSRC. Multistage stratified cluster sampling — similar to the 1998 study — was employed to draw a countrywide random sample of 2,530 respondents of 18 years and older. Questionnaires were completed in English during personal interviews. Interviewers explained questions in vernacular languages. The final realized sample consisted of the following: 1,802 Blacks (71.2\%), 323 Coloureds (12.8\%), 66 Indians (2.6\%), and 328 Whites (13.0\%) of which 221 were Afrikaans-speaking and 107 English-speaking (11 respondents did not respond to the question on race).

Respondents were asked to indicate on a 5-point scale the extent to which various social and cultural groupings were important to their sense of identity. The social groups varied from subnational groups (racial and ethnic groups), national groups such as the South African nation (the "Rainbow Nation"), and the South African state, to supranational groups and cultures (African culture, the Western world, Western culture, and the global community). The response options ranged 
from very important (5) to not important at all (1). Statistical analyses similar to those indicated for Study 1 were conducted.

\section{Results}

The Wilks's lambda statistic of .086 for the overall effect of the groups on the eight dependent variables for the multivariate analysis of variance was approximated by $F(4,2,427)=3,212.187 ; p<.001$. One of the most conspicuous results of this study is that the univariate analyses comparing the groups on each identity indicated that Afrikaans-speaking Whites identified significantly less than all other groups with the Rainbow Nation, while Blacks and Indians identified the strongest with this category [see Table $1, F(2,2,427)=19.353, p<0.001, \eta_{p}^{2}=$ .031]. The differences between the means of Blacks, Coloureds, and Englishspeaking Whites were not statistically significant. Indians identified the strongest with the South African state, while Blacks, Coloureds, and English-speaking Whites also indicated relatively high levels of identification with this category, $F(4,2,427)=7.391, p<0.001, \eta_{p}^{2}=.012$. Similar to the trend for the Rainbow Nation, Blacks, Indians, and English-speaking Whites also had a significantly higher mean than Afrikaans-speaking Whites regarding the South African state.

The smallest effects were those for identification with ethnic groups, $F(4$, $2,427)=5.165, p<.001, \eta_{p}^{2}=.008$, and racial groups, $F(4,2,427)=7.058, p<$ $.001, \eta_{p}^{2}=.012$. The limited size of the between-group differences, as well as the relatively high mean scores for all groups for these categories, furthermore indicate that South Africans of all groups attach high value to their respective ethnic and racial groups. The fact that racial and ethnic identities coexisted with national identities is also confirmed by the fact that Indians, in addition to identifying strongly with the Rainbow Nation and the South African state, also indicated the highest level of identification with their racial group. The mean scores for Blacks and Afrikaans-speaking Whites regarding racial identification were also relatively high. In contrast, Coloureds and English-speaking Whites identified less with their respective racial groups. Only one group comparison was statistically significant for ethnic identification-Coloureds identified significantly less strongly with their ethnic group than Indians.

The highest effect size was found for African culture, $F(4,2,427)=75.192$, $p<.001, \eta_{p}^{2}=.110$. The possibility of an African identity as an emerging divisionary factor in South Africa is furthermore confirmed by the fact that Blacks identified with African culture significantly more than Coloureds and both White groups. Coloureds also identified significantly more than Afrikaans-speaking Whites with this category, while the mean score for Indians was also higher than those for both White groups. In contrast, the mean for Afrikaans-speaking Whites was significantly lower than it was for all three groups of color. English-speaking Whites also identified significantly less than Blacks and Indians with this category. The second 
and third largest effect sizes were reported for Western culture, $F(4,2,427)=$ $39.467, p<.001, \eta_{p}^{2}=.061$, and the Western world, $F(4,2,427)=23.248$, $p<.001, \eta_{p}^{2}=.037$. English-speaking Whites identified significantly more than any other group with the Western world and Western culture. They also identified significantly more than Blacks and Coloureds with the global community. Blacks, on the other hand, identified significantly less with the Western world and culture than Indians and the two White groups, while Coloureds also identified significantly less with these two categories than both White groups. Note that Afrikaans-speaking Whites also identified significantly less with the Western world and culture than English-speaking Whites. English-speaking Whites also identified significantly more with the global community than Blacks and Coloureds, $F(4,2,427)=5.342, p<.001, \eta_{p}^{2}=.009$.

The results of the repeated measures analysis of variance indicate the existence of significant within-group differences, $F(4,2,218)=32.19 ; p<.001, \eta_{p}^{2}=$ .050. Although African culture apparently became the most important source of identification for Blacks as they assigned the highest importance rating to this category, the differences between their mean scores for African culture, the Rainbow Nation, Black ethnic groups, and their racial identity (Blacks), were not statistically significant. This means that they attached high value to identities related to their cultural, racial, and ethnic groups, as well as to the Rainbow Nation. Their mean scores for these categories were significantly higher than for all other social categories investigated, including the South African state.

For Coloureds no significant differences were found between their mean scores for the Rainbow Nation, the South African state, and their racial and ethnic groups. Similar to 1998, Coloureds apparently did not distinguish much between national and subnational categories. Their mean scores for these four categories were, however, significantly higher than for Western culture, the Western world, and the global community. Coloureds also identified significantly more with the Rainbow Nation than with African culture. It thus appears that supranational categories were not very important to Coloureds.

Similar to Coloureds, no significant differences were found for Indians for the Rainbow Nation, the South African state, and their racial and ethnic group. However, the mean scores for these categories also did not differ significantly from those for African culture and the Western world. Although the mean scores for these categories differed significantly from those for Western culture and the global community, it appears that Indians distinguished even less than Coloureds between social categories and identified strongly with most categories related to the South African context.

Afrikaans- and English-speaking Whites gave the highest importance ratings to their respective ethnic groups. With the exception of their racial group, Afrikaans-speaking Whites identified significantly more strongly with their ethnic group than with any other social category investigated. Especially noteworthy is 
the fact that Afrikaans-speaking Whites gave the lowest importance ratings to the Rainbow Nation, the South African state, and African culture. It appears that their identification with their ethnic group became stronger at the expense of national identities and identities associated with the wider world, while their racial group could be perceived as an extension or dimension of their ethnicity. Similar to Indians and Coloureds, English-speaking Whites did not distinguish strongly between groups. They identified, however, significantly less with African culture than with the Rainbow Nation, the South African state, and their ethnic group.

A noteworthy tendency is the fact that higher importance ratings were given throughout to localized identities such as the Rainbow Nation and ethnic and/or racial groups than for supranational identities. The only exception was African culture, which was important to Blacks and Indians, and Western culture, which was valued by English-speaking Whites.

\section{Discussion}

General conclusions should be drawn with care as different samples and different measures for investigating social identification were employed. It is, however, possible to draw attention to indications of possible emerging tendencies.

The results of the three studies indicate some possible changes in the identity structures of South Africans that can be ascribed, among others, to the social and political changes since the 1990s (Korf \& Malan, 2002). These changes are all related to the interface between national, subnational, and supranational identities. Whereas the nation-building initiatives of the postapartheid government have met with mixed success, both subnational and supranational identities play a role in the lives of South Africans. Their relative importance is apparently determined by the way in which both individuals and groups experience not only the South African context, but also the larger world of which they have become an integral part (Bekker, 1999; Le Pere \& Lambrechts, 1999; Mattes, 1999).

Among Blacks, the 1994 study indicated strong racial, South African, and ethnic identities, while an Africanist identity was subordinate to these. This situation seemed to have changed by 2001. Identification with their racial and ethnic group, and the notion of the South African Rainbow Nation, remained important to Blacks. However, confirming the findings of Gibson and Gouws (2000), identification with African culture seemed to have become a primary identity-for Blacks more so than for other groups, except Indians.

Gaining political power in 1994 has also strengthened Blacks' identification with the South African state and society (Mattes, 1999). The political transformation has also implied reintegration with the world and, particularly, reaffirmation of their African cultural roots. Africanism has consequently become a primary identity - confirming Eaton's (2002) viewpoint that a drive toward Africanization and the establishment of an African identity has largely replaced the 
nation-building discourse in South Africa. As Blacks identified significantly less with Western culture, the Western world, and the global community than most other groups, it appears that this group may favor engagement with Africa over engagement with the West or the global community.

In contrast, losing political power has apparently led Afrikaans-speaking Whites to withdraw to the confines of their ethnic group. Despite the differences in the wording of questions, all three studies indicated strong ethnic identification among Afrikaans-speaking Whites. However, the 1994 study showed that they also identified strongly with South Africans. In 1998 they furthermore voiced high pride in being South Africans. However, the results of the 2001 study revealed that Afrikaans-speaking Whites identified significantly less than all other groups with the notion of the Rainbow Nation. They also identified significantly less with the South African state than Blacks, Indians, and English-speaking Whites. Unlike English-speaking Whites, they did not identify particularly strongly with identities relating to their Western roots and the global community. In congruence with an interpretation given by Mattes (1999), being on the periphery of power may have resulted in Afrikaans-speaking Whites identifying less with prominent national and supranational identities. Their ethnic group has apparently become their refuge in the new dispensation.

Both the 1998 and 2001 studies indicate that Indians identify strongly with their ethnic and racial group, but they also hold strong nationalistic attitudes since they indicated high pride in being South Africans and also identified strongly with the Rainbow Nation. Coloured identity appears to be more ambivalent. In 1998, Coloureds voiced significantly less pride than Blacks in being South Africans. They were also significantly less close to their language group than Blacks and Afrikaans-speaking Whites. In 2001 they identified significantly less than Blacks and Indians with their racial groups and also significantly less than Blacks with their ethnic group. Overall, it appears that Coloureds do not identify particular strongly with any subgroup. Their strongest identity seems to be with the South African nation.

In 1994, English-speaking Whites identified primarily with their ethnic group, and with South Africa. A significant number of English-speaking Whites were strong opponents of apartheid and identified more strongly with South Africa in the period immediately after the new dispensation than before. However, in 1998 this group indicated less pride in being South African, and less closeness to their language, racial, and ethnic groups than did the other groups. However, in 2001 they again indicated their preferred identification with their ethnic group, while they did not differ significantly from most of the other groups with regard to racial and ethnic identification. It appears that the strong South African identity at the expense of racial and ethnic identification has waned somewhat. English-speaking Whites nevertheless still indicated relatively strong identification with the Rainbow Nation and the South African state in 2001. English-speaking Whites, with their 
strong roots in the United Kingdom and Europe furthermore appear to be the group with the strongest global and Western orientation, as they identified significantly more than most of the other groups-even Afrikaans-speaking Whites-with Western culture, the Western world, and the global community.

The results of all three studies confirm the results of other researchers that ethnicity and race-ethnicity in particular-have not vanished with the inception of the so-called new South Africa (Finchilescu \& Dawes, 1999; Gibson \& Gouws, 2000; Klandermans et al., 2001; Mattes, 1994). On the contrary, both categories appear to be thriving. The vitality of race and ethnicity in the new dispensation confirms the warning sounded by Horowitz (1991) that racial and ethnic groups will not necessarily cease to exist in a new, democratic dispensation but could instead flourish and meet important psychological and social needs of their members. As highlighted by the 1998 study, language appears to be the primary indicator of culture and/or ethnicity. Language differences consequently serve as the most important factor that distinguishes various ethnic and/or cultural groups in South Africa.

By and large, it appears that localized identities - both national and subnational-are more important to the majority of South Africans than supranational and global identities. Important exceptions are Africanism for Blacks and, to a lesser extent, Western culture for English-speaking Whites. The results of the 2001 study provide some evidence that cultural tension could be emerging in South African society, as the largest between-group differences were found for identification with African culture. A gulf could be developing between Africanoriented and other cultures. This conclusion is confirmed by the fact that Blacks also identified significantly less with Western culture than all the other groups, and significantly less with the Western world than the two White groups. However, more research is needed to determine the dynamics and consequences of these differences.

The conclusion can be drawn that the advent of a democratic political dispensation in South Africa has not eradicated and/or solved the problems of heterogeneity, diversity, and potential identity conflict. Given the fact that social identities have an important impact on the self-concepts of individuals and their attitudes and behavior, which in turn can influence intergroup relations and social and political stability, policy makers need to pay attention to issues related to identity formation. Although the fostering of an overarching national identity remains important, the existence of subnational identities should not be ignored, but rather embraced. It is particularly important to create space for language identities to flourish. It might also become problematic to propagandize an identity such as Africanism as not all South Africans seem to identify with this.

As identity structures are continuously formed, reformed, and changed by the ongoing social and political dynamics within broader society and the world (Korf \& Malan, 2002), ongoing research—especially in heterogeneous societies 
such as South Africa - is necessary to determine the potential political, social, and psychological consequences of identity structures, and changes in these structures, for individuals, groups, and societies. Major shortcomings of the current research are that only broad tendencies are identified, and the fact that one-dimensional measures were employed for investigating identification with various categories. Future research should focus on in-depth analyses - taking into account the influence of variables such as age (generation), gender, and level of education. The usefulness of multi-item and/or multidimensional measures for variables such as national identities should also be investigated. Comparative research with other societies could furthermore throw light on the complex interplay between subnational, national, and supranational identities.

\section{References}

Bauman, Z. (1998). Globalization: The human consequences. Cambridge, UK: Polity.

Bekker, S. (1999). Introduction: Recent development in identity studies. In S. Bekker \& R. Prinsloo (Eds.), Identity? Theory, politics, history (pp. 1-9). Pretoria, South Africa: Human Sciences Research Council.

Bornman, E. (2003). Struggles of identity in the age of globalisation. Communicatio, 29, $24-47$.

Bornman, E. (2006). National symbols and nation-building in the post-apartheid South Africa. International Journal of Intercultural Relations, 30, 383-399.

Deaux, K. (1993). Reconstructing social identity. Personality and Social Psychology Bulletin, 19, 4-12.

Eaton, L. (2002). South African national identity: A research agenda for social psychologists. South African Journal of Psychology, 32, 45-53.

Erasmus, Z. (2010). Contact theory: Too timid for "race" and racism. Journal of Social Issues, 66, $389-402$.

Finchilescu, G., \& Dawes, A. (1999). Adolescents' socio-political perspectives on South African society: An investigation into the effects of social change between 1992 and 1996. Unpublished report on the project conducted for the Centre for Science Development, University of Cape Town, South Africa.

Finchilescu, G., \& Tredoux, C. G. (2010). The changing landscape of intergroup relations in South Africa. Journal of Social Issues, 66, 223-236.

Gibson, J. L., \& Gouws, A. (2000). Social identities and political intolerance: Linkages within the South African mass public. American Journal of Political Science, 44, 272-286.

Helms, J. E. (1990). Introduction: Review of racial identity terminology. In J. E. Helms (Ed.), Black and white racial identity: Theory, research and practice (pp. 9-32). New York: Greenwood Press.

Horowitz, D. L. (1991). A democratic South Africa? Constitutional engineering in a divided society. Berkeley: University of California Press.

Human Sciences Research Council. (1987). The South African society: Realities and future prospects. Contributions to Ethnic Studies, Number 21. Westport, CT: Greenwood Press.

Klandermans, B., Roefs, M., \& Olivier, J. (2001). The state of the people: Citizens, civil society and governance in South Africa, 1994-2000. Pretoria: HSRC.

Korf, L., \& Malan, J. (2002). Threat to ethnic identity: The experience of White Afrikaans-speaking participants in post-apartheid South Africa. Journal of Social Psychology, 142, 149-169.

Le Pere, G., \& Lambrechts, K. (1999). Globalisation and national identity construction: Nation building in South Africa. In S. Bekker \& R. Prinsloo (Eds.), Identity? Theory, politics, history (pp. 1138). Pretoria, South Africa: Human Sciences Research Council.

Mattes, R. (1994). Survey unpacks April '94. Democracy in Action, 8, 12-14. 
Mattes, R. B. (1999). Hypotheses on identity and democracy: Community, regime, institutions and citizenship. In S. Bekker \& R. Prinsloo (Eds.), Identity? Theory, politics, history (pp. 151 - 180). Pretoria, South Africa: Human Sciences Research Council.

Schopflin, G. (1997). Civil society, ethnicity and the state: A threefold relationship. Retrieved July 14, 2003, from http://http://www.ssees.ac.uk/gs1.htm.

Sleek, S. (1993). A call to lay down arms calls for cultural identity. APA Monitor, 24, 35.

Soudien, C. (2010). The reconstruction of privilege: Integration in former white schools in South Africa. Journal of Social Issues, 66, 353-367.

Tajfel, H. (1981). Human groups and social categories. Cambridge: Cambridge University Press.

Van Den Berghe, P. L. (1981). The ethnic phenomenon. New York: Elsevier.

ELIREA BORNMAN is associate professor in the Department of Communication Science at the University of South Africa. She completed a Dlitt et Phil in Social Psychology in 1995 at the Department of Psychology of the University of South Africa, dealing with ethnicity in South Africa during a period of social and political change. Her main research interests include social identification, intergroup relations and issues related to nation building and diversity in the postapartheid South Africa. 